\title{
Jogos Computacionais: uma proposta interdisciplinar de educação ambiental
}

\section{Herika Bastos de Medeiros ${ }^{1}$ Antonio Carlos de Miranda ${ }^{2}$}

Resumo: Este artigo aborda questões ambientais através de um jogo computacional (desenvolvidos pelos autores), envolvendo à sobrevivência humana e a sua relação com os conteúdos interdisciplinares da $3^{\mathrm{a}}$ série do Ensino Fundamental. Nesse sentido, busca-se associar o jogo à educação ambiental de forma interdisciplinar através da sua exploração e avaliação em sala de aula. Acreditamos que os jogos computacionais representam uma importante estratégia de ensino-aprendizagem favorecendo $o$ desenvolvimento cognitivo, a autonomia e a articulação com temas interdisciplinares. Palavras-chave: educação ambiental, jogo computacional, interdisciplinaridade.

Abstract: This article discusses environmental issues through the computational game, related to the human survival, and its relation with the interdisciplinary content of the $3^{\text {rd }}$ grade of the Elementary School. This way, we aim to associate the game to the environmental education in a interdisciplinary way. We believe the computational games represent an important learning teaching strategy, favoring the cognitive development, the autonomy and the articulation with interdisciplinary themes.

Keywords: environmental education, computational games, interdisciplinarity.

\section{Introdução}

Atualmente, o ambiente natural é degradado em uma velocidade jamais registrada antes. Segundo Leff (2007), a problemática ambiental - a poluição, a degradação e a crise de recursos naturais, energéticos e de alimentos - gerou mudanças globais em sistemas socioambientais complexos "que afetam as condições de sustentabilidade do planeta, propondo a necessidade de internalizar as bases ecológicas e os princípios jurídicos e sociais para a gestão democrática dos recursos naturais."

A crise ambiental passa a ser também uma crise civilizatória. E para que os problemas sejam superados, são necessárias mudanças na concepção do mundo, de natureza, poder e bem-estar, tendo como base valores individuais e sociais.

\footnotetext{
Para outros, ainda, o homem deveria se comportar não como o dono do mundo, mas, percebendo-se como parte integrante da natureza, resgatar a noção de sacralidade da natureza, respeitada e celebrada por diversas culturas tradicionais, antigas e contemporâneas (PCN, 1997, p: 22)
}

De acordo com Morin (2010), os fenômenos são cada vez mais fragmentados, e não se consegue conceber a sua unidade, porque as disciplinas se fecham e não se comunicam umas com as outras e, na verdade, não se articulam. Essa totalidade é fundamental para compreensão e ação equilibrada no ambiente, que é inteiro e não fragmentado. Já para os PCN's, a principal função do desenvolvimento de atividades envolvendo o tema Meio Ambiente

é contribuir para a formação de cidadãos conscientes, aptos para decidireme atuarem na realidade socioambiental de um modo comprometido com a vida

\footnotetext{
1 Mestre em Ensino da Saúde e do ambiente (UNIPLI), Prof. da Rede Municipal de Itaboraí e São Gonçalo; herikabastos@yahoo.com.br

${ }^{2}$ Doutor (UNICAMP); Prof. do Programa de Pós-Graduação Stricto Sensu- UNIPLI; miratam@ig.com.br
} 
com o bem-estar de cada um e da sociedade, local e global. Para isso, é necessário que, mais do que informações e conceitos, a escola se proponha a trabalhar com atitudes, formação de valores e com o ensino e a aprendizagem de habilidades e procedimentos (PCN, 1997, p: 29)

Atento a essas questões, esta investigação tem como objetivo desenvolver um software educativo e, fundamentalmente, avaliar a sua adequação à sala de aula, de modo que seja um instrumento de ensino-aprendizagem, visando a exploração de conteúdos interdisciplinares associados à educação ambiental que desempenhem um papel ativo na própria realidade dos fatos observados e que apresentam preocupação com a sobrevivência humana.

Uma problemática fundamental que envolve a investigação seria como desenvolver software educativo de modo que seja um instrumento eficaz para trabalhar conteúdos interdisciplinares associados à educação ambiental.

O novo transdisciplinar deveria fundar-se no paradigma da complexidade, o único capaz de promover um tipo de comunicação sem redução, pois

nasce ao mesmo tempo do desenvolvimento e dos limites das ciências contemporâneas: "o pensamento complexo é animado por uma tentativa permanente entre a aspiração a um saber não fragmentado, não compartimentado, não redutor, e o reconhecimento do inacabamento e da incompletude de todo conhecimento (Morin apud Japiassu, 2006, p: 66)

Sendo assim, o educador, ao planejar constantemente a sua prática e tendo como referência os objetivos e conteúdos propostos, fará com que essas atividades tenham um fim em si mesmo, atento a essa questão esta pesquisa pretende também contribuir na formação de futuros cidadãos conscientes. Nesse sentido, optou-se como estratégia de ensino aprendizagem o jogo, que potencializa a exploração e a construção do conhecimento por contar com a motivação interna típica do lúdico (KISHIMOTO, 1984). Por sua vez, Vygotsky comenta que "a cultura forma a inteligência e a brincadeira favorece a criação de situações imaginárias e reorganiza experiências vividas". Assim, a grande importância do jogo no desenvolvimento deve-se ao fato de criar novas relações entre situações dos pensamentos e situações reais.

Nessa concepção, é de fundamental importância motivar e incentivar o interesse do educador para a elaboração de uma proposta pedagógica, que respeite as diversidades e a cultura local. Sendo assim, faz-se necessário tornar a educação ambiental parte integrante dos currículos, estimulando uma nova postura em relação à questão ambiental.

\section{Material e Método}

Esta investigação apresenta-se como uma pesquisa qualitativa de caráter exploratória descritiva, cujo objetivo é promover a participação dos estudantes na exploração e avaliação de um jogo educativo.

O traçado metodológico desta pesquisa desenvolve-se em cinco etapas: na primeira etapa, constrói-se um levantamento das principais revistas científicas de educação ambiental e sua interface com o lúdico; na segunda etapa, apresenta-se a análise de conteúdo dos livros didáticos e sua relação com o software educativo; na terceira etapa, apresenta-se a construção do jogo; na quarta etapa, o desenvolvimento do jogo e na quinta e última etapa, o registro e análise que envolve a aplicação do jogo.

O cenário da pesquisa foi a Escola Municipal Presidente Castello Branco, localizada na sede do Município de São Gonçalo, bairro Boaçu. Os sujeitos da pesquisa 
foram dez alunos do $3^{\circ}$ ano do Ensino Fundamental e a sua professora. Nesse cenário, foram analisados materiais pedagógicos, tais como o livro didático, a grade curricular e o conteúdo programático do $3^{\circ}$ ano do ensino fundamental, visando à construção do software educativo adequado ao conteúdo previsto pela unidade escolar e pelo MEC.

Ressaltamos a relevância e atualidade do tema desta pesquisa, ao despertar o interesse do aluno por questões ambientais como lixo, água, formas geométricas e sustentabilidade, ao mesmo tempo, relaciona os conteúdos escolares que se articulam com temas que envolvem questões ambientais do cotidiano do aluno e do próprio município no qual residem. Portanto, em consonância com a lei $\mathrm{n}^{\mathrm{o}}$ 9.975/99, que estabelece o Plano Nacional de Educação Ambiental, afirma em seu artigo $2^{\circ}$ que "a educação ambiental é um componente essencial e permanente na educação nacional, devendo estar presente de forma articulada em todos os níveis e modalidades do processo educativo, em caráter formal e não-formal".

Em uma etapa inicial, tornou-se necessário averiguar na literatura o envolvimento do lúdico na educação ambiental atualmente. O levantamento foi feito em revistas da área da educação ambiental identificando os artigos que fazem interface com o lúdico no processo de ensino-aprendizagem. A tabela abaixo mostra as revistas eletrônicas pesquisadas entre janeiro de 2008 e dezembro de 2010.

Tabela 1: Revistas eletrônicas da área ambiental selecionadas para a realização do levantamento sobre o lúdico/educação ambiental (entre janeiro de 2008 e dezembro de 2010)

\begin{tabular}{l}
\hline Revista Ambiental em Ação \\
\hline Revista Eletrônica do Mestrado em Educação \\
Ambiental (REMEA) \\
\hline Revista Brasileira de Pesquisa em Educação em \\
Ciências \\
\hline Revista Ambiente \& Educação \\
\hline Revista Ensino, Saúde e Ambiente \\
\hline
\end{tabular}

Nas revistas analisadas foram publicados 525 artigos $\mathrm{e}$ foram identificados apenas nove que abordavam a educação ambiental e o lúdico.

Em outra etapa da pesquisa, analisamos os livros adotados pela unidade escolar, foi possível perceber que as formas de organização são bem semelhantes, independente da disciplina. Apresentam particularidades de seu ambiente regional e desenvolvem temas transversais com a preocupação de mostrar atitudes favoráveis à convivência, com atividades de observação, comparação, pesquisa, elaboração de hipóteses e conclusões. A partir dessa análise, buscou-se estabelecer uma sintonia entre a elaboração do jogo e os conteúdos dos livros didáticos, por exemplo, no 'Jogo da Geometria', os temas abordados são os seguintes: Simetria, Eixo de simetria, Retângulo, Triângulo e Círculo. Ainda no mesmo jogo, constatamos que os seguintes conteúdos estão presentes nas seguintes disciplinas (livros didáticos): Matemática - Cálculos, figuras geométricas, figuras planas, figuras não planas e simetria; Geografia - $\mathrm{O}$ bairro: lugar para viver e paisagens dos bairros e representação da paisagem do bairro; e Ciências - Catavento.

No 'Jogo do Meio Ambiente', os seguintes temas são abordados: Lixo, Poluição, Localização Geográfica, Reciclagem do Lixo, Zonas Urbana e Rural. Nesse jogo, constatamos que os seguintes conteúdos são trabalhados, pelas seguintes disciplinas (livro didático): Língua Portuguesa - Convivência- Cuidando do meio ambiente, Cartas e outras mensagens, Propaganda é a alma do negócio, Convivência - poluição; 
Matemática - Figuras planas e não planas, De olho nos números - economizando água, Usando a Matemática - motivos para separar o lixo, Figuras planas e não planas; Geografia - Problemas com o bairro, o ambiente em perigo, tipos de poluição, Representação da paisagem do bairro, fotografias, plantas e maquetes, Como encontrar lugares, a localização no espaço, o bairro e o município, zona urbana e zona rural; História - o lugar onde eu moro, vivendo nas cidades; Ciências - terra cheia de vida, ninguém vive sem água.

\subsection{Construção do Jogo}

Para construir os jogos educacionais, escolhemos o Macromedia Flash MX 8.0, um programa utilizado na criação de animações interativas e aplicações, através da linguagem voltada para objetos Actionscript. A interface gráfica do Flash 8.0 permite que mesmo usuários iniciantes possam, de maneira simples, dispor de seus recursos, mesmo sem conhecimentos sólidos de programação.

Para confecção dos jogos educativos utilizamos o 'Template de Quis', contido no Flash $8.0^{1}$. Pode-se dizer que cada frame é uma parte do jogo. Por padrão, eles estão dispostos da seguinte forma: 1- Tela de boas vindas; 2- Interação Drag and Drop (jogo de "arrastar e largar"); 3- Interação Fill in the blank (jogo de "preencher a lacuna");4Interação Hot Objects (jogo de "acender o objeto"); 5-Interação Hot Spot (jogo de "evidenciar o objeto"); 6-Interação Multiple Choice (jogo de "múltipla escolha"); 7Interação True or False (jogo do "verdadeiro ou falso"); 8-Tela de pontuação.

Para produzir um jogo, deve-se entrar em cada uma dessas telas e editá-las, alterando seus componentes através da modificação dos parâmetros e importação de figuras ou outros arquivos. Cada componente dos frames é alimentado pela biblioteca (library). Dentro da biblioteca, estão as pastas com os arquivos que alimentam os componentes dos jogos. Navegando pelas pastas, encontramos os componentes de cada jogo e partes gráficas das cenas. Para testar o jogo, deve-se escolher a opção CONTROL>TEST MOVIE e com o jogo finalizado, escolhe-se o menu FILE>PUBLISH SETTINGS. Em seguida, na aba FORMATS, marca-se o formato de saída do jogo. O mais recomendado é o formato.exe, pois já produz o jogo de forma compilada, que abre ao clicar sobre ele.

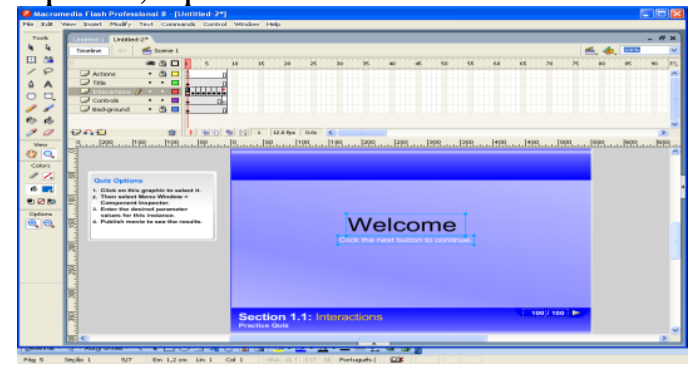

Figura 1:- Tela de boas vindas

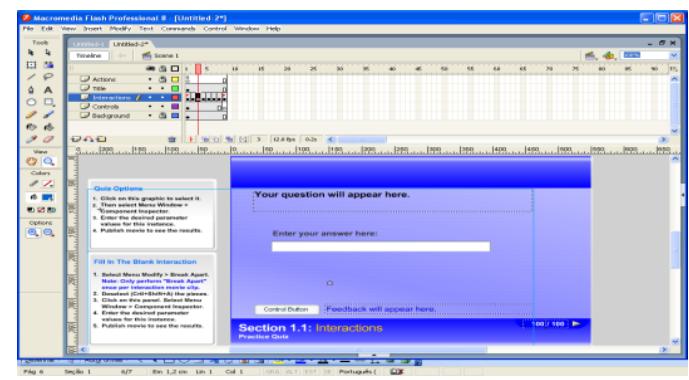

Figura 3:- Interação Fill in the blank

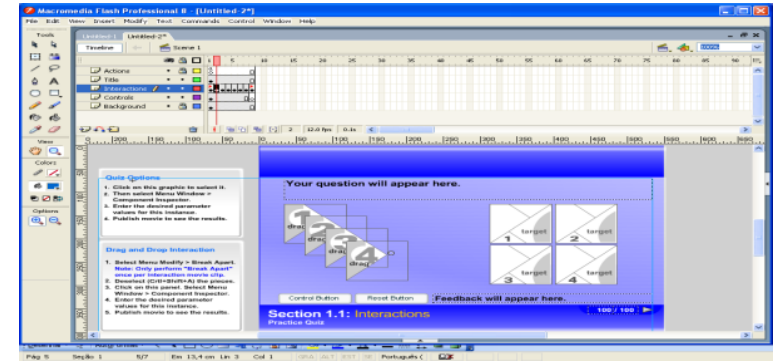

Figura 2:- Interação Drag and Drop

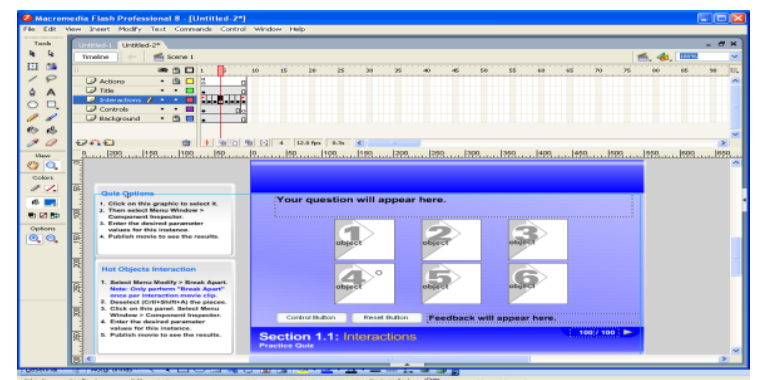

Figura 4:- Interação Hot Objects 


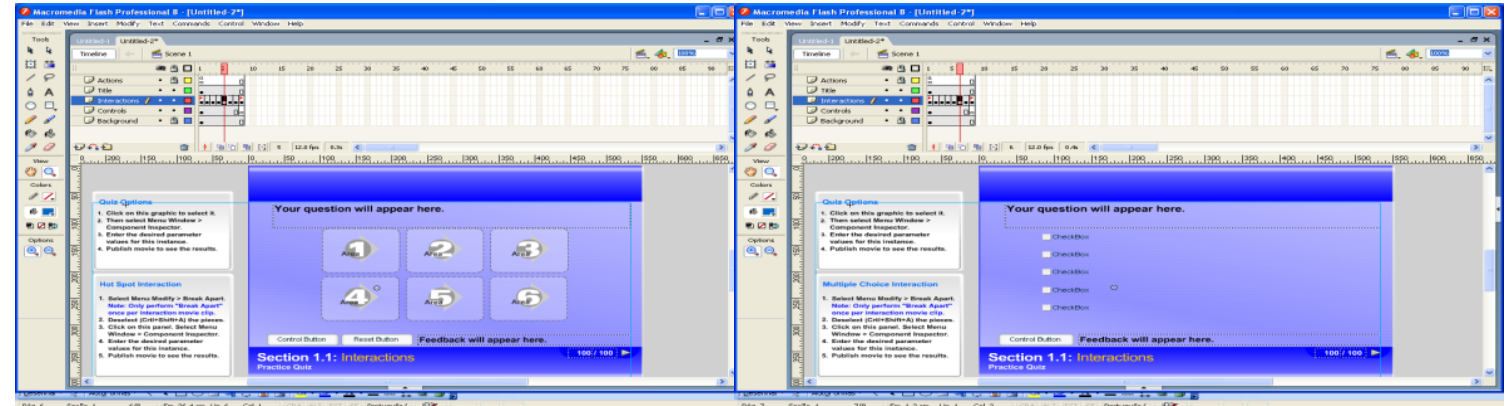

Figura 5:- Interação Hot Spot

Figura 6: -Interação Multiple Choice

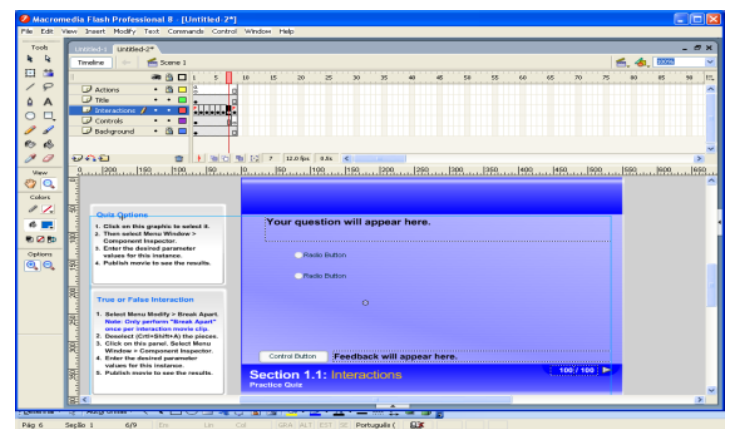

Figura 7:- Interação True or False

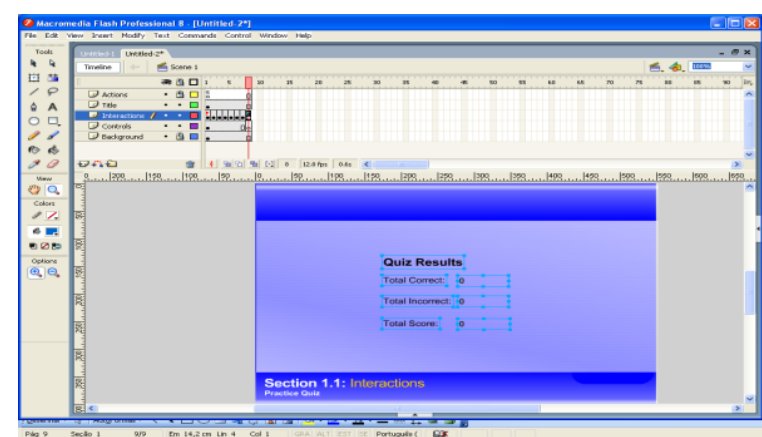

Figura 8:-Tela de pontuação

\subsection{Desenvolvimento dos Jogos}

Inicialmente, é bom destacar que o jogo visa trazer à tona e avaliar os conhecimentos relacionados aos conteúdos programáticos contidos nos livros didáticos e abordados em sala de aula. Vale lembrar que, na fase de planejamento da construção do jogo, analisamos os conteúdos programáticos (Ciências, Matemática, História, Geografia, Português e Informática) dos livros didáticos citados anteriormente, procurando, de forma interdisciplinar, explorá-lo através dos jogos. Nessa fase da pesquisa, estivemos também atentos ao projeto político pedagógico (PPP) da unidade escolar e ao Plano de curso em relação aos temas propostos. Por outro lado, estivemos atentos as palavras de Passos e Behar (2011) quando afirmam que "o estudo da interface torna-se fundamental para o processo educativo. É necessário, então, que os materiais educacionais digitais sejam planejados e construídos visando a possibilitar uma postura ativa do sujeito".

$\mathrm{O}$ aluno, ao iniciar o jogo, lerá na primeira tela o release do jogo e identificará a sua temática. Em cada setor que percorrer e avançar, ele terá a resposta correta com a pontuação obtida ou a mensagem "resposta incorreta". As perguntas serão compostas por imagens, onde cada uma delas poderá conter uma ou mais opções corretas. O aluno, após responder todas as perguntas no final do jogo, obterá o total da sua pontuação, que poderá variar entre 0 a $100 \%$ de acertos. Para cada pergunta, existem opções de 'clicar' na resposta correta, marcar uma única opção, arrastar as partes da figura para compor a imagem ou encaixar objetos nos seus respectivos lugares. Ao 'clicar' na opção errada, aparecerá uma mensagem indicando o erro e a possibilidade de jogar mais uma vez. Ao acertar a questão, surgirá uma mensagem que o encaminhará para a próxima pergunta. Ao término do jogo, é emitida a mensagem na tela de pontuação. 
Jogo do Meio Ambiente: Na primeira tela, apresenta-se a 'tela de boas vindas'. Na segunda tela (Fig. 9), solicita-se ao aluno que arraste os diferentes objetos para a lixeira correspondente. Cabe lembrar, que a questão do lixo faz parte do conteúdo programático e representa uma preocupação atual. Para Miranda, Gomes e Silva (2006), o crescente desenvolvimento urbano acelera esse processo, pois são geradas quantidades de resíduos tóxicos originados de produtos que fazem parte do uso no dia-a-dia, tais como pilhas, lâmpadas, produtos de limpeza em geral, inseticidas entre outros, que vão ter como destino os lixões. Já na terceira tela (Fig. 10), propõe-se que o aluno 'clique' no gráfico identificando qual dos materiais apresentam o maior índice de lixo reciclado. $\mathrm{Na}$ quarta tela (Fig. 11), solicita-se que o aluno arraste com o mouse para a caçamba de lixo os três objetos que estão poluindo o meio ambiente.

È importante ressaltar que o conteúdo programático da série escolar envolvida na pesquisa apresenta um tema que envolve a descrição de zona urbana e zona rural, tendo como preocupação direcionar a atenção do aluno para além da realidade local e, ao mesmo tempo, conscientizando-os da realidade global. É útil para o educando e para a escola enquanto instituição conhecer os limites definidos pela prefeitura do município para a área urbana. Nesse caso, deve-se proporcionar aos alunos situações que envolvam a comunidade e a cidadania, oportunizando exercitar valores de tomadas de decisões individuais, coletivas e institucionais. Atento a essa temática, na quinta tela (Fig. 12), apresentam-se imagens do Município de São Gonçalo, onde o aluno irá selecionar aquela que representa a zona rural e urbana. Por fim, na sexta tela (Fig. 13), apresentase um mapa contendo alguns bairros de São Gonçalo. Nela, solicita-se ao aluno que 'clique' na figura que representa o bairro onde se localiza a escola. Quando o aluno finalizar esta tela, deverá 'clicar' com o mouse no botão "parar". Ele saberá que é a última tela do jogo (Fig. 14) porque aparecerá o índice 6/6 na parte inferior dela.

O tempo de permanência no jogo somente será registrado se o aluno 'clicar' no botão "começar" e no final, na última tela, clicar no botão "parar". O tempo é armazenado no banco de dados para a definição do ranking. Para ter acesso ao ranking, o aluno deverá digitar o nome, seu tempo e o percentual obtido no final do jogo e clicar com o mouse no comando "enviar para o ranking".

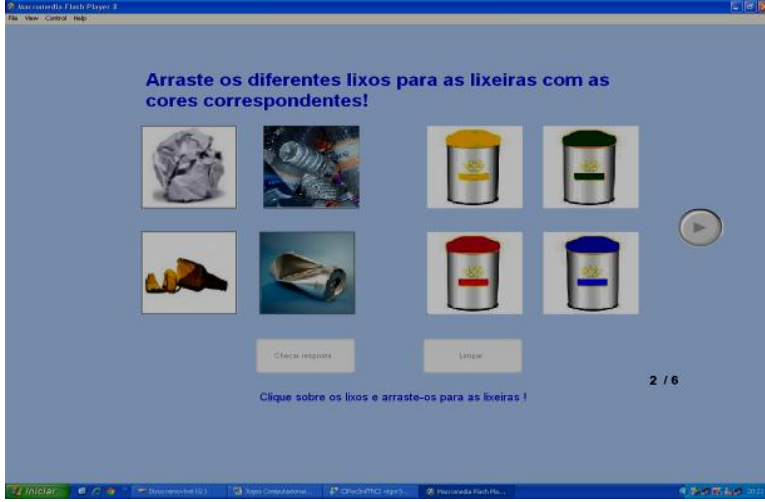

Figura 9- Segunda tela do Jogo do Meio Ambiente

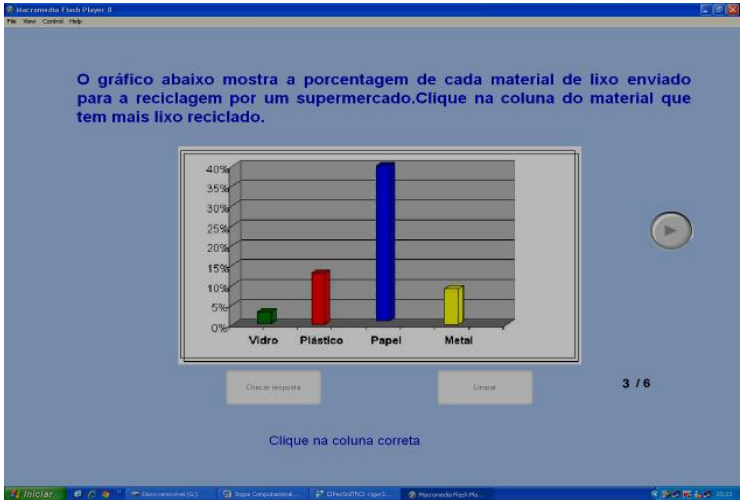

Figura 10- Terceira tela do Jogo Meio Ambiente 


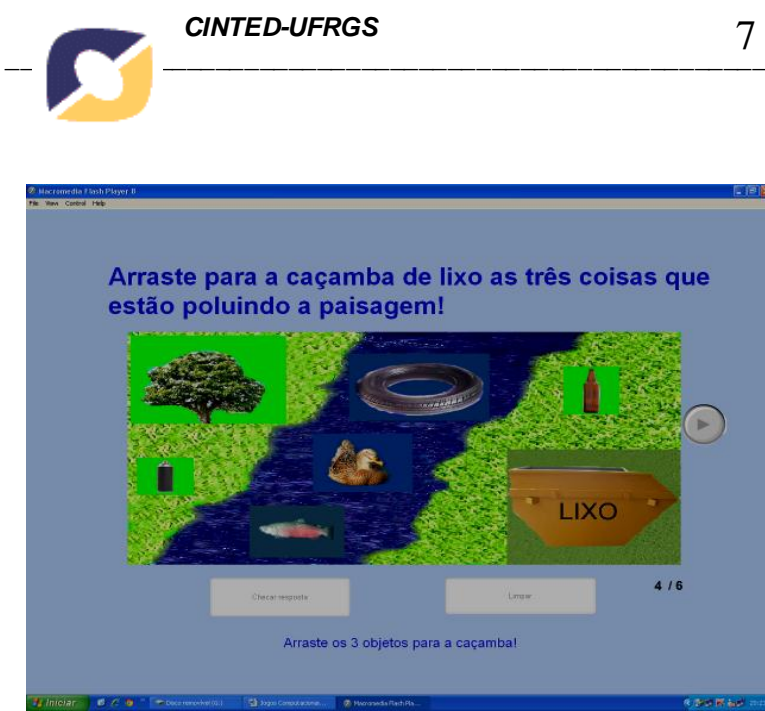

Figura 11- Quarta tela Jogo do Meio Ambiente
Todos os municipios brasileiros saà formados por uma área
rural e uma área urbana. Observe as fotografias de alguns rural e uma area urbana. Observe as fotografias de algun pontos
rural.

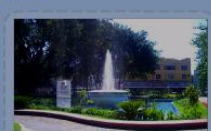

$+$

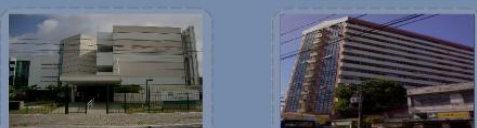

$5 / 6$

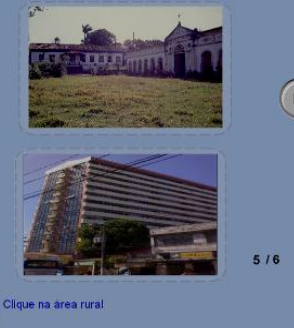

Figura 12- Quinta tela do Jogo do Meio Ambiente

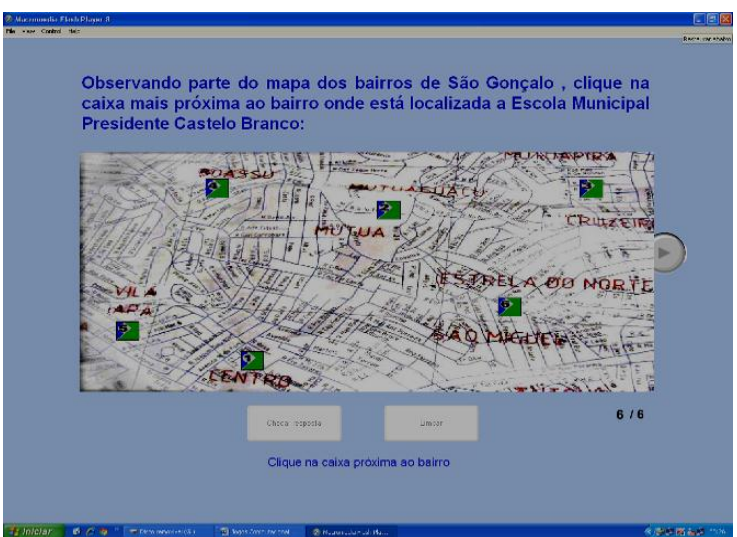

Figura 13- Sexta tela do Jogo do Meio Ambiente

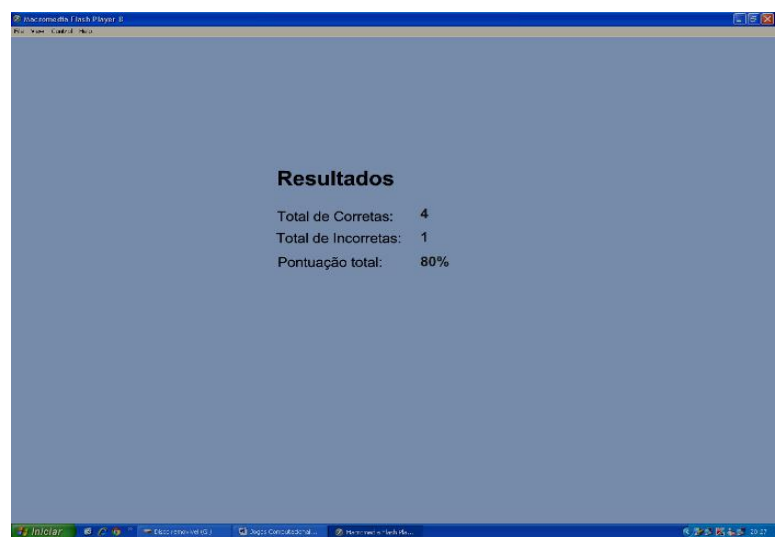

Figura 14- Sétima tela do Jogo do Meio Ambiente

Jogo da Geometria: Ao concluir o Jogo do Meio Ambiente, na tela surgirá automaticamente o release, onde aparecem os dois jogos e seus respectivos rankings. $\mathrm{O}$ aluno deverá agora clicar no segundo jogo.

$\mathrm{Na}$ primeira tela, apresenta-se a proposta do jogo. Em seguida (Fig. 14), surge a imagem simétrica de uma borboleta e pede-se ao aluno que arraste as peças e monte a borboleta. Na tela seguinte (Fig. 15), apresenta-se a Igreja Matriz de São Gonçalo "São José do Amarante" e que o aluno identifique os círculos, triângulos, retângulos e o eixo de simetria na figura, 'clicando' com o mouse. A seguir (Fig. 16), que o aluno monte um quebra-cabeça a partir de figuras do trevo de quatro folhas. Nessa tela, o aluno deverá 'clicar' com o mouse no comando "parar".

Cabe destacar que a simetria é um tema importante no estudo da Matemática, principalmente na geometria, e, além disso, é uma característica que pode ser observada na natureza e em várias vertentes da ação humana. Nesse sentido, buscou-se trazer a imagem da borboleta e do trevo como exemplos de espécies da natureza em que isso ocorre, ao mesmo tempo, estabelecendo um vínculo com o meio ambiente. Por outro lado, a imagem da Igreja Matriz acentua essa ação humana, já que representa uma obra arquitetônica que a vincula ao espaço urbano do Município e ao cotidiano dos alunos. De acordo com os DCN's, as noções geométricas favorecem o aluno a desenvolver a compreensão do mundo em que vive, estabelecendo conexões entre a Matemática e outras áreas.

Por fim, na última tela, apresenta-se o total de questões corretas, incorretas e a pontuação obtida em percentual. 


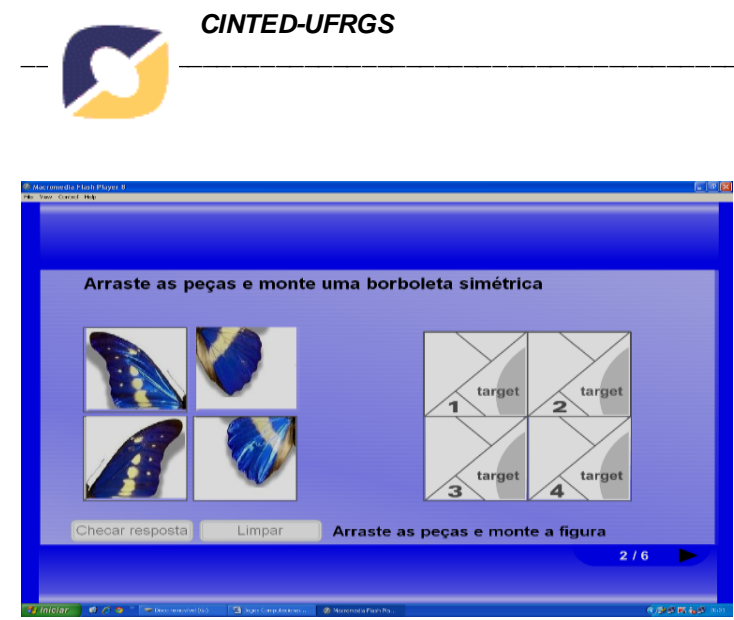

Figura 15-Segunda tela do Jogo da Geometria

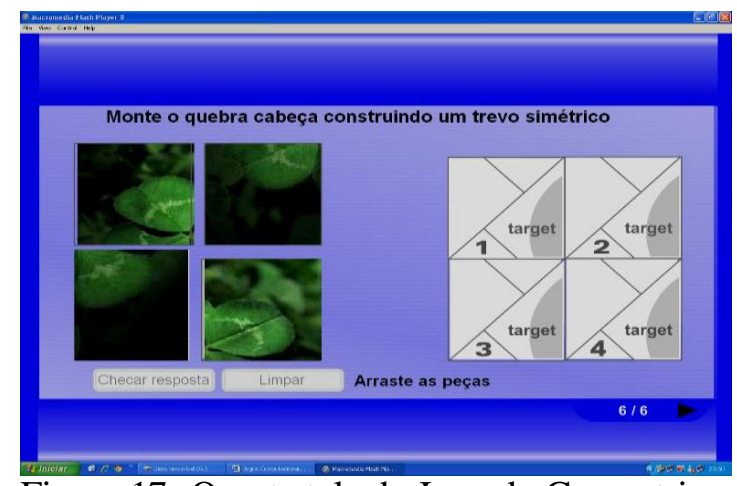

Figura 17- Quarta tela do Jogo da Geometria

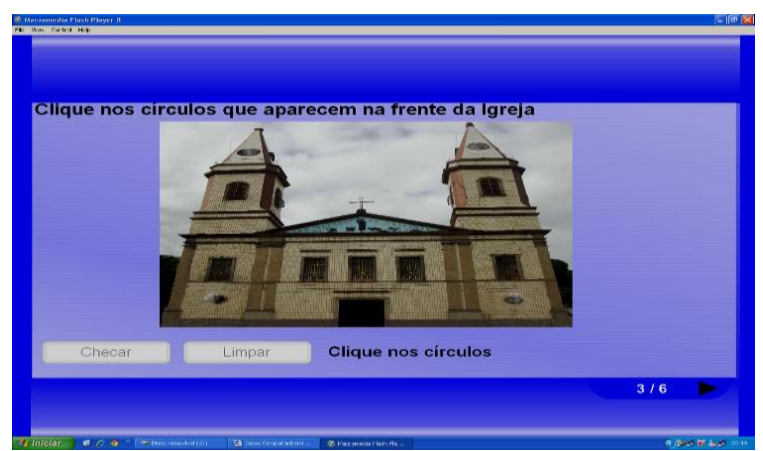

Figura 16- Terceira tela do Jogo da Geometria

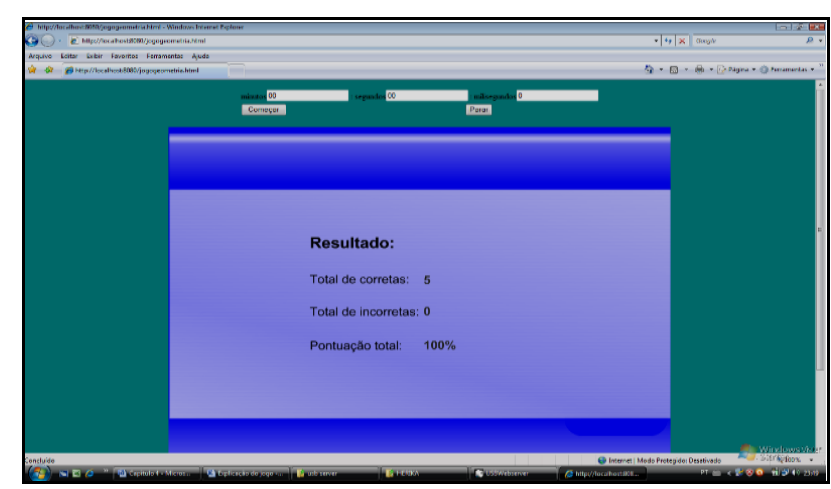

Figura 18- Segunda tela do Jogo da Geometria

\section{Avaliação pelos alunos:}

* Que jogo você achou mais fácil?

$-70 \%$ dos alunos consideraram o jogo da geometria, $20 \%$ o jogo do meio ambiente e $10 \%$ os dois jogos.

*Que parte do jogo você mais gostou?

-50\% apontaram para o Jogo da Borboleta, $40 \%$ para o Lixo na Caçamba e 10\% para todos;

*Que etapa do jogo você obteve maior dificuldade?

O gráfico a seguir representa as respostas dos alunos:

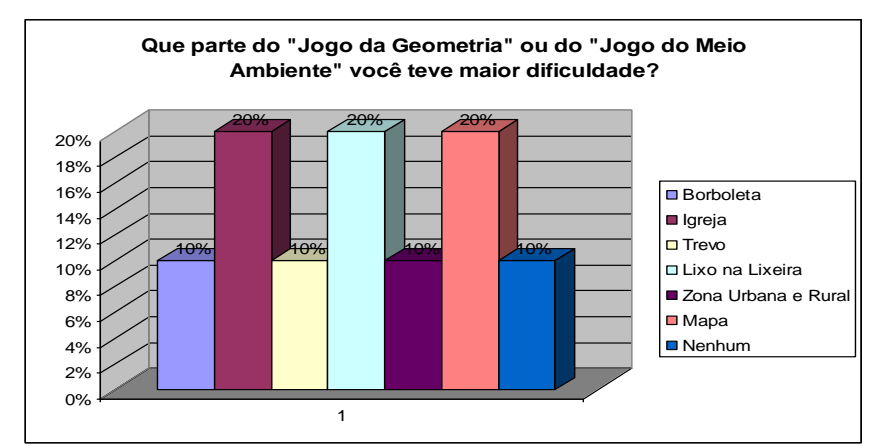

Gráfico 1: Parte do Jogo que o aluno teve maior dificuldade

Identificamos uma maior dificuldade nos jogos em que envolveram as temáticas: 'Igreja', 'Lixo na lixeira' e 'Mapa'. Na etapa do jogo acerca da imagem da Igreja, percebemos que os alunos, em sua maioria, conhecem as figuras geométricas inseridas na imagem, mas sempre a associam como elas apresentam-se nos livros, e passam a ter dificuldade quando isso não ocorre. Na verdade, o jogo trouxe à tona esta dificuldade $\mathrm{e}$ também propiciou a possibilidade de discussão deste tema, e a adequação de trazer figuras geométricas que possam fazer parte do cotidiano dos alunos. Outra dificuldade 
dos alunos foi relativa à identificação das lixeiras, a figura com as lixeiras está no livro didático, e o professor abordou este tema. No entanto, quando o aluno se vê em uma situação em que precisa utilizar este conteúdo, não consegue responder corretamente, isto é, utilizá-lo de fato. O que sugere que este tema não faz parte do seu cotidiano. E que a própria escola pode e deve ter estas lixeiras em suas dependências e estimular o seu uso. Já o jogo envolvendo o mapa, o seu resultado sugere que o mapa do Município não é familiar aos alunos. No entanto, esse diagnóstico indica que nos três casos selecionados o jogo teve um papel importante, não apenas ao trazer à tona essas dificuldades, mas também como uma importante forma de ensino e aprendizagem, ao fazer o aluno refletir sobre estes conteúdos e, fundamentalmente, sob uma nova estratégia, motivados a apreendê-los.

Os resultados da pesquisa, portanto, estão em ressonância, entre outros, com o pensamento de Vygotsky (1984) quando afirma que "a cultura forma a inteligência e a brincadeira favorece a criação de situações imaginárias e reorganiza experiências vividas". Por sua vez, Kishimoto (2002) diz que a utilização do jogo potencializa a exploração e a construção do conhecimento por contar com a motivação interna típica do lúdico. Por outro lado, segundo (Juca apud Freire, 2006), o aluno deve ser capaz de participar desse mundo que cada vez mais se compõe de ambientes informatizados. Por sua vez, Marcon e Teixeira (2011) afirmam "que essas tecnologias passam a possuir papel fundamental na sociedade contemporânea, uma vez que é através delas que a comunicação e o diálogo entre pessoas que não dispõem da condição presencial se efetivam". Nessa linha, David (2002) defende o ponto de vista que a participação da criança na mídia, deve ser vista como extremamente positiva para os jovens em busca de autodesenvolvimento, autonomia progressiva e de interação completa.

\section{Considerações finais}

Inicialmente identificamos que estudos envolvendo jogos computacionais são pouco explorados nas revistas científicas da área ambiental. Percebemos, ainda, que os jogos representam uma importante estratégia de ensino-aprendizagem.

Acreditamos que o uso do lúdico aplicado em software educativo possibilita a elaboração de situações que envolvem os Temas Transversais atrelados aos conteúdos programáticos, facilitando a abordagem de questões relativas à Educação Ambiental, em sala de aula. Além disso, permite envolver conteúdos motivadores e que apresentam significados com as questões do cotidiano do município em que os alunos vivem.

Por outro lado, percebemos que, em conjunto com a construção de atividades lúdicas, deve-se buscar também a implantação de Educação Ambiental no Projeto Político Pedagógico, elaborando ações pedagógicas que perpassem pelas disciplinas, conforme orientações da Lei 9795/99, com suas recomendações para auxiliar os docentes na compreensão da transversalidade de EA. Além disso, deve-se elaborar novas pautas nas reuniões pedagógicas com o corpo docente, com objetivos de ampliar conhecimentos de EA, romper com a visão tradicional e motivando o docente a ser um articulador do aprendizado, construindo novos olhares em novas relações entre homem, sociedade e natureza, através de uma proposta crítica, reflexiva e contínua em EA, que o lúdico, o jogo e a informática podem propiciar.

\section{Notas de texto}

A Educação do futuro deve enfrentar o problema de dupla face do erro e da ilusão, deve mostrar que não existe conhecimento que não esteja, em algum grau, ameaçado pelo erro e ilusão.

${ }^{2}$ Por padrão, os três templates de Quis do Flash 8.0 são simplesmente uma cena composta de oito frames. 


\section{Referências}

Apostila Macromedia Flash - Avançado com Actionscript. Disponível em <http://www.baixaaqui.com.br> , acessado em 20 de março de 2011.

BRASIL, Lei no. 9394/96- Diretrizes e Bases da Educação Nacional. LDB/MEC/SEFParâmetros Curriculares Nacionais para o Ensino Fundamental: Meio Ambiente e Saúde. Temas Transversais, $1^{\text {a }}$ a $4^{\text {a }}$ série. 1997.

BRASIL, Lei no . 9394/96- Diretrizes e Bases da Educação Nacional. LDB/MEC/SEFParâmetros Curriculares Nacionais para o Ensino Fundamental: Meio Ambiente e Saúde. Temas Transversais, $1^{\mathrm{a}}$ a $4^{\mathrm{a}}$ série. 1997.

DAVID, P. Os Direitos da Criança e a Mídia: Conciliando proteção e participação. In: ULlA, C; FEILITZEN, C. A criança e a Mídia. Imagem, Educação, Participação. São Paulo: Editora Cortez, p. 37-41. 2002

JAPIASSU, Hilton. O sonho transdisciplinar e as razões da filosofia. Rio de Janeiro: Imago, 2006.

JUCA, S. C. A relevância dos softwares educativos na educação profisssional: Ciência e Cognição, vol.08, p. 22-28, 2006.

KISHIMOTO. T. M. Jogos Infantis: o Jogo a Criança e a Educação. $10^{a}$ edição. Petrópolis: Vozes, 2002.

KNEIPP, R. E.; MIRANDA, A. C.; ALBUQUERQUE, R. C. Jogos na Web: instrumentos de ensino-aprendizagem de educação ambiental no ensino fundamental. Revista Iberoamericana, n.38/2, mar.2006.

LEFF, Henrique. Epistemologia Ambiental. São Paulo, Editora Cortez, 2007.

MARCON, K.;TEIXEIRA, A. C. Informática na Escola: uma visão da gestão. Revista Novas Tecnologias na Educação, Rio Grande do Sul. v. 9, n. 1, jul, 2011.

MIRANDA, A. C.; GOMES, H. P., SILVA, M. O. Recursos Hídricos: A Gestão das águas, a Preservação da Vida. Rio de Janeiro: Editora All Print, 2006.

MORIN, Edgar. Ciência com consciência. 13ª edição. Rio de Janeiro: Bertrand, 2010.

PASSOS, P. C. S. J.; BEHAR, P. A. Interação e Interatividade através de materiais educacionais digitais. Revista Novas Tecnologias na Educação, Rio Grande do Sul. v. 9, n. 1, jul, 2011.

VIGOTSKY, Lev S. A formação social da mente: o desenvolvimento dos processos psicológicos superiores. São Paulo: Editora Martins, 1984. 